\title{
ON THE EARTHQUAKE OCCURRENCES IN JAPAN AND THE SURROUNDING AREA VIA SEMI MARKOV MODELING
}

\author{
Panorias C. ${ }^{1}$, Papadopoulou A. ${ }^{1}$ and Tsapanos T. ${ }^{2}$ \\ ${ }^{1}$ Department of Mathematics, Statistics and Operations Research Section, Aristotle University of \\ Thessaloniki,Thessaloniki 54124, Greece,xristos.panwrias@yahoo.com ${ }^{1}$, \\ apapado@math.auth.gr ${ }^{l}$ \\ ${ }^{2}$ Geophysical Laboratory, School of Geology, Aristotle University of Thessaloniki, Thessaloniki \\ 54124,Greece, tsapanos@geo.auth.gr ${ }^{2}$
}

\begin{abstract}
In the present paper, the earthquake occurrences in the area of Japan, are studied by a semi Markov model which is considered homogeneous in time. The data applied refer to earthquakes of large magnitude $\left(M_{w} \geq 6.0\right)$ during the period 1900-2012. We consider 9 seismic zones derived from the typical 11 zones for the area of Japan, due to the lack of data for 3 zones (9-th,10-th and 11-th). Also, we define 3 groups for the magnitudes, corresponding to 6-7,7.1-8 and $M>$ 8.0. Thus, we consider for our semi Markov model a finite state space, $S=\left\{\left(Z_{i}, R_{j}\right) \mid i=1, \ldots 9, j=1,2,3\right\}$, where $Z_{i}$ defines the $i$-th seismic zone and $R_{j}$ states the $j$-th magnitude scale. We applied the data to describe the interval transition probabilities for the states and the model's limiting behaviour for which is sufficient an interval of time of seven years. The time unit of the model is considered to be one day. Some interesting results, concerning the interval transition probabilities and the limiting state vector, are derived.

Keywords: semi-Markov model, earthquake occurrences, transition probabilities, limiting behaviour, Japan.

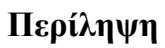

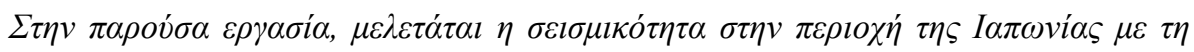

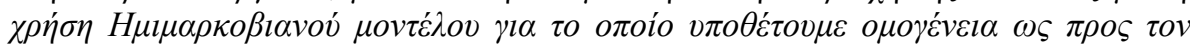

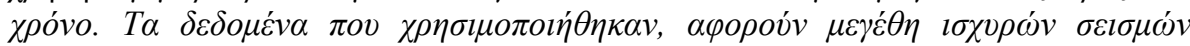

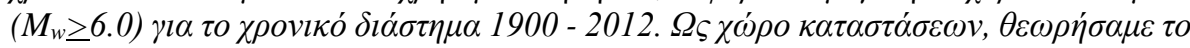

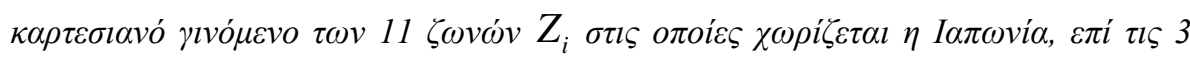

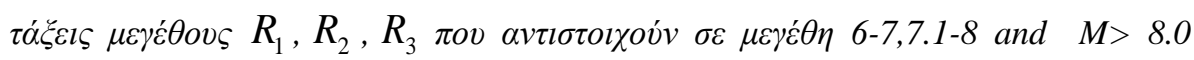

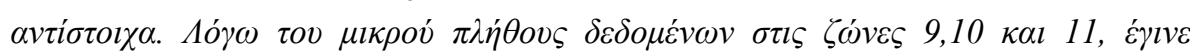

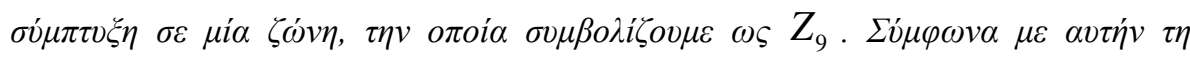

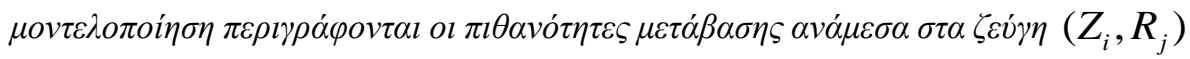

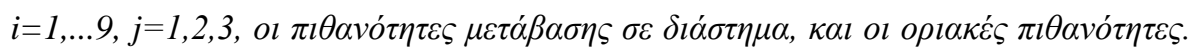

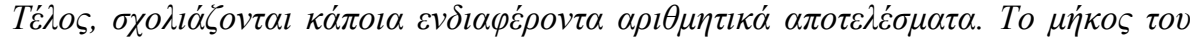

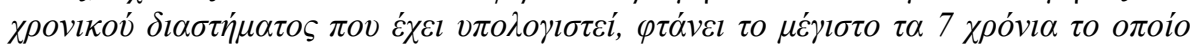




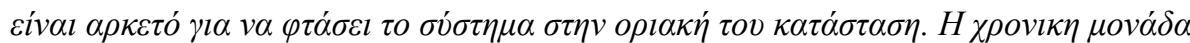

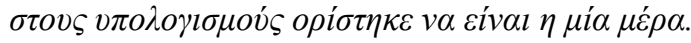

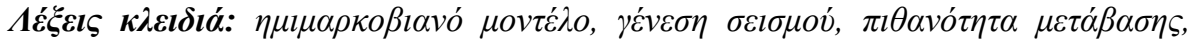

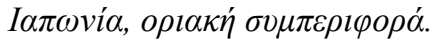

\section{Introduction}

Stochastic modeling is often applied for the study of earthquake occurrences. In literature, results on Markov and semi Markov modeling for the earthquake occurrences are presented in Vere-Jones (1966) and Knopoff (1971) where a continuous-time and continuous-state Markov process is applied to describe aftershock sequences as well as sequences of main shocks followed by aftershocks, respectively. Also, Lomnitz-Adler (1983) used a simulation of a Markov model to achieve a simplified representation of the spatial distribution of earthquakes on adjacent faults. Tsapanos and Papadopoulou (1999) applied a discrete Markov model for earthquake occurrences in southern Alaska and Aleutian islands. A prognostic process through a Markov model is described for an earthquake of $\mathrm{M}_{\mathrm{w}}=8.3$ in South America by Tsapanos (2001). Seismic hazard evaluation in the Japan area using Markov chains was studied by Nava et al. (2005). Karagrigoriou et al. (2015) made an attempt to describe zoning data as data of a multi-state system through Markov model and examine earthquake occurrence by assessing intensity rates and transition probabilities in seismic zones of South America. Spatio-temporal complex Markov chain used by Cavers and Vasudevan (2015) in global earthquake sequences and analyze the statistics of the transition probabilities linked to earthquake zones. A hidden semi Markov model is applied to reveal some key features of the earthquake generation process by Votsi et al. (2014).

In the present paper a semi Markov model is applied to data, referring to earthquake occurrences in the area of Japan through the time period 1900-2012. The data are of high magnitudes $\left(\mathrm{M}_{\mathrm{w}} \geq 6.0\right)$ in the 11 zones of the area of Japan which are shortened to 9 due to the lack of data for the zones 9,10 and 11. We define three groups for the magnitudes i.e. $R_{1}: 6-7 \mathrm{R}, R_{2}: 7-8 \mathrm{R}$ and $R_{3}: 8 \mathrm{R}$ and over. Considering the above definitions we can define a double state space, $\mathrm{S}=\left\{\left(Z_{i}, R_{j}\right) \mid \mathrm{i}=1, \ldots 9\right.$,

$\mathrm{j}=1,2,3\}$, where $Z_{i}$ defines the $\mathrm{i}$-th seismic zone and $R_{j}$ states the $\mathrm{j}$-th magnitude scale. The time unit of the model is defined to be one day and the transition probabilities between the states are supposed to be homogeneous in time. The implementation of the previous referred data produced interesting numerical results for the interval transition probabilities and the limiting state probabilities. A time period of seven years is sufficient for the model to achieve its limiting behaviour.

\section{The data}

The earthquakes occurred in Japan and its vicinity area extracted from NEIC catalogue. The time span is 113 years, starting from 1900 to 2012. Only large earthquakes having magnitudes $M_{w} \geq 6.0$ are considered for the purpose of the present study. The earthquake magnitudes of the catalogue used are not provided in a unique scale. Local magnitudes, body wave magnitudes, etc. are listed. For this reason and because there is a need for a unique magnitude scale, we converted all magnitudes in moment magnitude scale $\mathrm{M}_{\mathrm{w}}$, using for this purpose the empirical relationships (Scordilis 2006) by considering data from the whole earth. So, our sample is constituted of 276 events with magnitudes $\mathrm{M}_{\mathrm{w}} \geq 6.0$. Only main shocks are processed and for this scope we used a method introduced by Musson et al. (2002). The data of the present study are restricted to the shallow $(\mathrm{h} \leq 60 \mathrm{Km}$ ) events only (Shcherbakov et al., 2013). The whole examined area is divided to 9 zones (states) following the separation made by Musson et al. (2002). Some slight modifications were made to these zones for the scope of this study. Specifically, zones 9, 10 and 11 are considered as one, named zone 9 (Fig. 1). 


\section{Tectonic environment and seismicity of Japan}

The tectonic environment of Japan and its vicinity is depicted in Figure (2). Many great interplate earthquakes with $\mathrm{M}_{\mathrm{w}} \geq 8.0$ have occurred and it is obvious that a strong coupling on the plate boundary exists (Kanamori, 1977). Ito et al. $(1999,2000)$ applied an inversion analysis of GPS in order to find the spatial distribution of the interplate coupling in northwest and southeast Japan. Great earthquakes have occurred repeatedly along the Nankai trough with recurrence time ranged between 90 and 150 years (Thatcher, 1984).

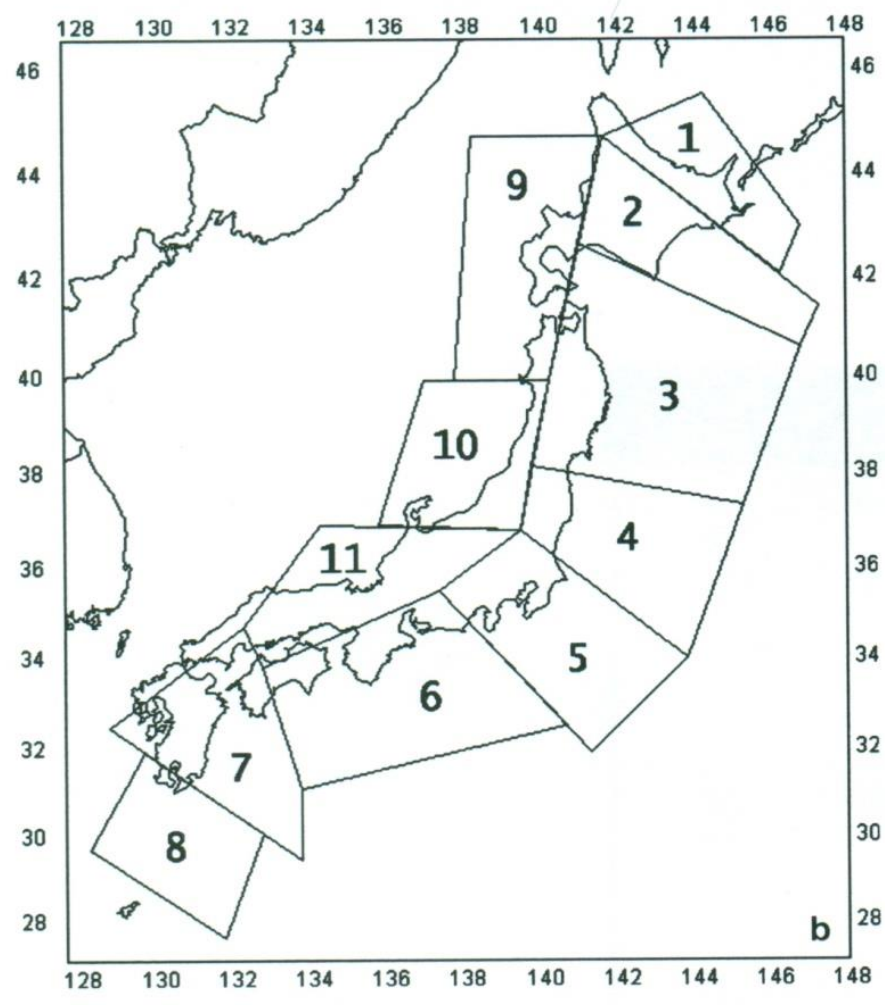

Figure 1 - The seismic zones considered for Japan. Inland zones 9, 10 and 11 are modified as one single zone.

The most characteristic shocks were the ones which occurred in Nankai during 1944 with $\mathrm{M}_{\mathrm{w}}=7.8$, while the other one generated in its vicinity in 1946 having a magnitude $M_{w}=8.0$. It is believed that these two events released accumulated stress in association with the subduction of the Philippine plate. A giant earthquake of magnitude $\mathrm{M}_{\mathrm{w}}=9.0$ occurred to Japan Trench on 11 of March 2011. Coulomb stress studied by Sato et al. (2012), defines that changes for normal fault aftershock near the Japan Trench, showed a strong association with the slip on the shallow portion of faults.

Most of the large shallow earthquakes in Japan along the plate boundaries (inteplate seismicity) show in general low-angle thrust mechanisms resulting from the subduction process and all of them are generated on the land part of the trench (Ando, 1975).

Matsuda (1981) divided Japan into 12 seismogenic sources based on seismotectonics and geomorphological criteria. The same author (Matsuda 1990) separated by fault the area into 11 seismic zones, relying on seismic activity. Wesnousky (1984) integrated geological and seismological data to determine probabilistic seismic zoning in Japan. Papazachos et al. (1994) divided the broader area of Japan into seismogenic sources, somehow different from those of 
Matsuda, for prediction purposes. A different approach for seismic zoning in Japan, is published by Karakaisis (2000) which is based on regional time predictable seismicity model.

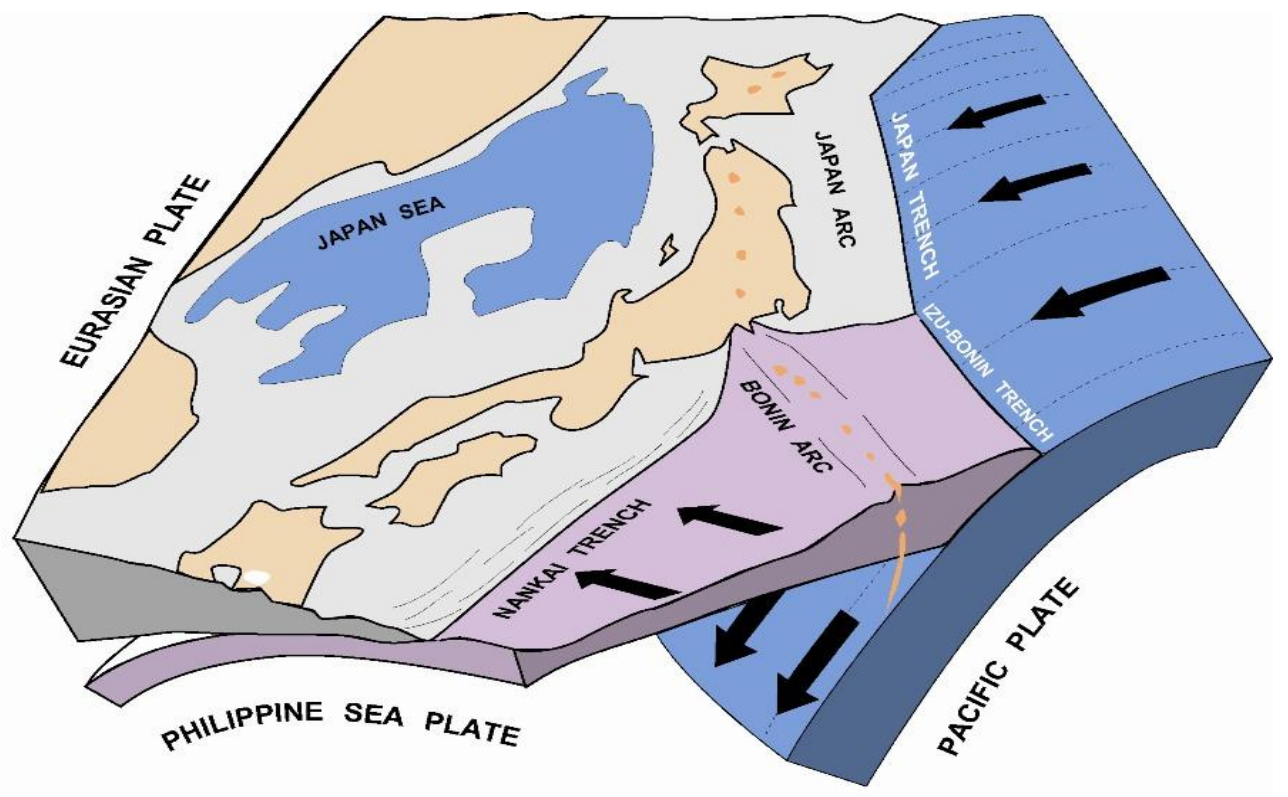

Figure 2 - The tectonic regime of Japan and its surrounding area (after eartjay.com).

\section{The semi Markov model}

A semi Markov model, is defined by the following basic parameters: the state space, the embedded Markov chain and the sequence of matrices of the holding time distributions for every state. Thus, in our model we have the following:

- The state space, is finite and discrete and is defined as $\mathbf{S}=\left\{\left(Z_{i}, R_{j}\right) \mid i=1, \ldots 9, j=1,2,3\right\}$ where $Z_{9}$ is the union of zones 9,10 and 11 .

- The embedded Markov chain is defined by the matrix $\boldsymbol{P} \in M_{27 \times 27}(\mathbb{R})$, with elements the transition probabilities between the states i.e. $\boldsymbol{P}=\left\{p_{i j}\right\} i, j \in S$ where $p_{i j}$ are estimated by the relative frequencies $\frac{n_{i j}}{n_{i}}, \forall i, j \in S, n_{i j}$ defines the frequency of earthquake occurrences to state $j$ given that the previous earthquake occurred in state $i$ and $n_{i}$ is the frequency of earthquake occurrences in state $i$.

- The sequence of matrices of the holding time distributions is defined by $\{\boldsymbol{H}(m)\}_{m=1}^{\infty}$ where $\boldsymbol{H}(m)=\left\{h_{i j}(\mathrm{~m})\right\}_{m=1}^{\infty} i, j \in S$, and $h_{i j}(\mathrm{~m})=\frac{n_{i j(m)}}{n_{i j}}, i, j \in \boldsymbol{S} . n_{i j}(m)$ defines the frequency of earthquake occurrences to state $j$ given that the previous earthquake occurred in state $i$ with holding time equal to $m$ and $n_{i j}$ defines the frequency of earthquake occurrences to state $j$ given that the previous earthquake occurred in state $i$.

Remark: From the data, we get that the frequencies for the states $\left(\mathrm{Z}_{4}, \mathrm{R}_{3}\right),\left(\mathrm{Z}_{7}, \mathrm{R}_{3}\right),\left(\mathrm{Z}_{8}, \mathrm{R}_{3}\right),\left(\mathrm{Z}_{9}, \mathrm{R}_{3}\right)$ are equal to zero so the corresponding elements of the matrices $\mathbf{P}, \mathbf{H}(\mathrm{m}), \mathbf{Q}(\mathrm{m})$ are removed. Matrix $\mathbf{P}$ is given below: 
Table 1 - Matrix $P$ of the transition probabilities for the states, $S=\left\{\left(Z_{i}, R_{j}\right) \mid i=1, \ldots 9\right.$, $j=1,2,3\}$.

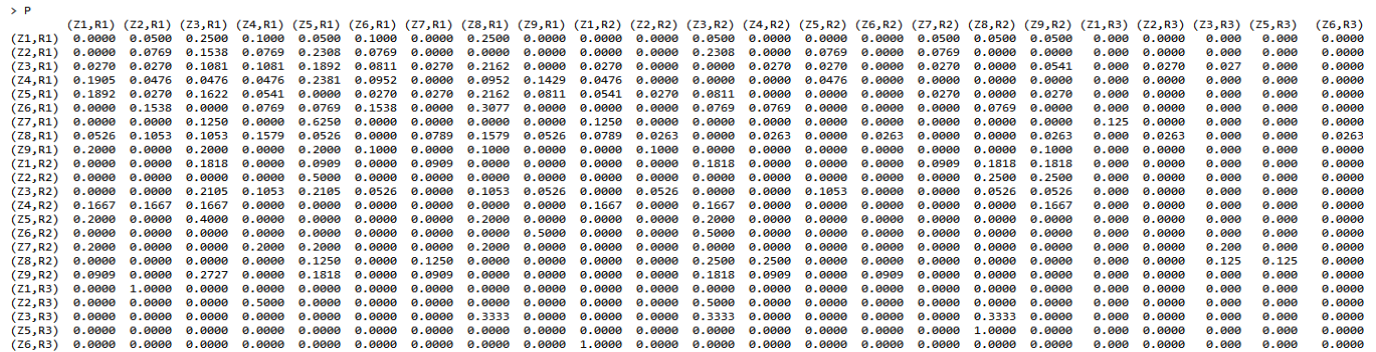

There are some transition probabilities equal to 1: (Z1,R3)--> (Z2,R1), (Z5,R3)--> (Z8,R2) and (Z6 ,R3)--> (Z1,R2), and a remarkable transition probability $62,5 \%$ for the transition: $(Z 7, R 1)-->(Z 5$, R1). (Probabilities equal to 1 , are questionable, because these states occurred only one time each).

Now let $\boldsymbol{Q}(n) \in M_{23 \times 23}(\mathbb{R})$ the matrix with elements the interval transition probabilities $q_{i j}(n)$. Then

$\boldsymbol{Q}(n)={ }^{>} W(n)+\sum_{m=1}^{n} \boldsymbol{C}(m) \cdot \boldsymbol{Q}(n-m)$ (Howard, (1971)) where $\boldsymbol{C}(m)$ is the core matrix for the semi Markov model $\left(\boldsymbol{C}(n) \ni c_{i j}(n)=p_{i j} \cdot h_{i j}(n), i, j \in S, n \in\{1,2, \ldots\}\right)$ and ${ }^{>} W(\cdot)$ is a diagonal matrix with elements equal to the survival probabilities for the holding times.

\section{Application}

Concerning following results, we have to mention that were produced by code developed in $\mathbf{R}$ (Ver3.1.3).

Indicatively, for $n=2500$, the matrix $\boldsymbol{Q}(2500)$, is given in Table 2:

Table 2 - Matrix $Q(2500)$ of the interval transition probabilities, $S=\left\{\left(Z_{i}, R_{j}\right) \mid i=1, \ldots 9\right.$, $j=1,2,3\}$.

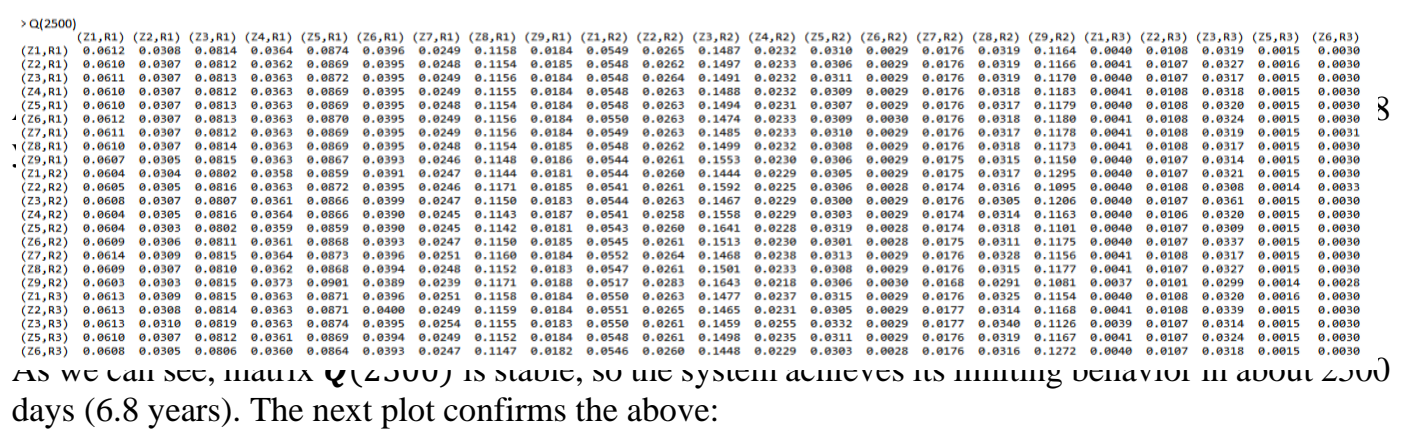




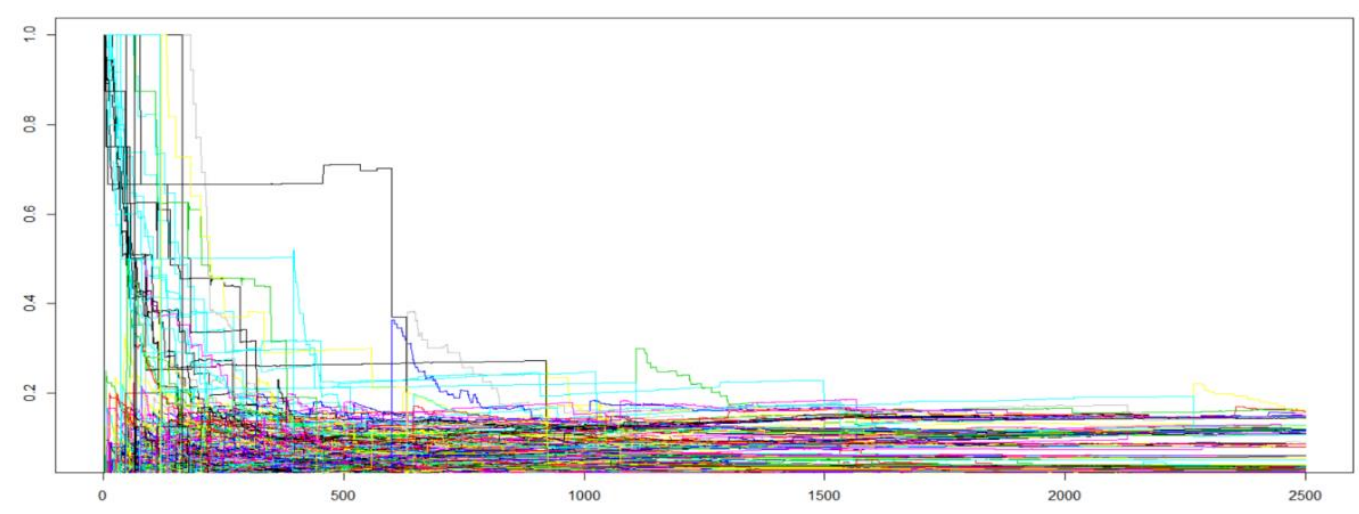

Figure 3 - A plot for $m \epsilon\{1,2, \ldots, 2500\}$ of $q_{i j}(m), \forall i, j \in S$.

If we arrange all the earthquake occurrences from 1900 until 2012 in ascending chronological order and if we define as $X_{i}$ the moving average of the holding times with order 11 then, $X_{i}=$ $E\left(\left\{\tau_{k}\right\}_{k=i-10}^{k=i+10}\right), i \in\{11, \ldots, 265\}$ where $E$ is the mean operator. The plot of $X_{i}$ is given below:

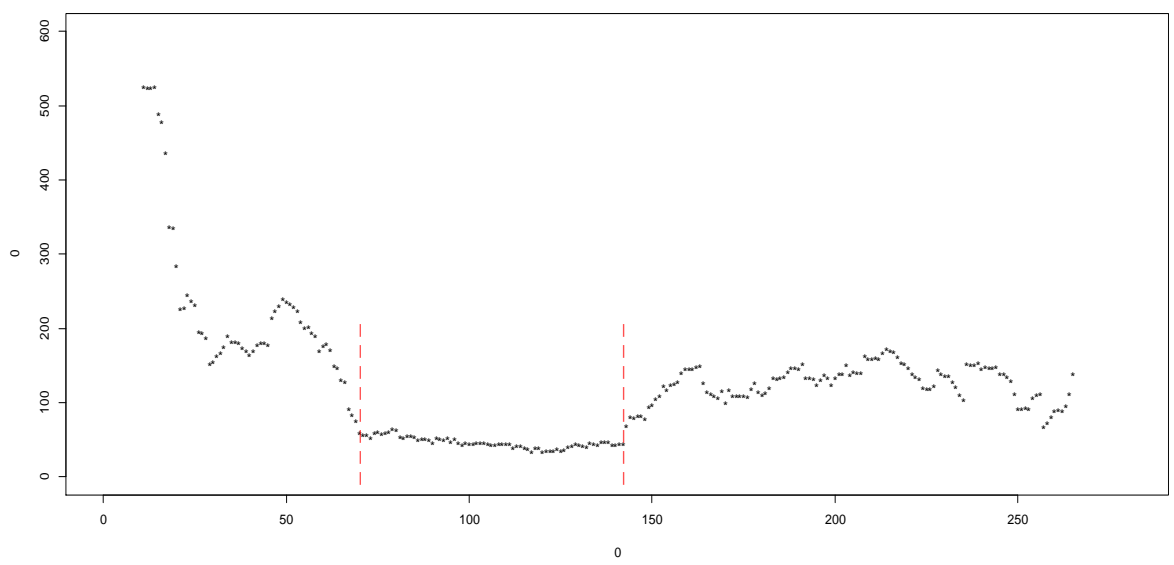

Figure 4 - Plot of $\boldsymbol{X}_{\boldsymbol{i}}=\boldsymbol{E}\left(\left\{\tau_{k}\right\}_{k=i-10}^{k=i+10}\right)$.

The boundary lines indicate the time interval where the mean holding time before the next earthquake is 48.3 days. Before and after the bounded area, the mean holding times are 215.16 and 133 days correspondingly. The earthquakes in the above mentioned interval occurred from 20/10/1954 until 01/06/1964. The frequencies of the zone occurrences are described below in Fig.5

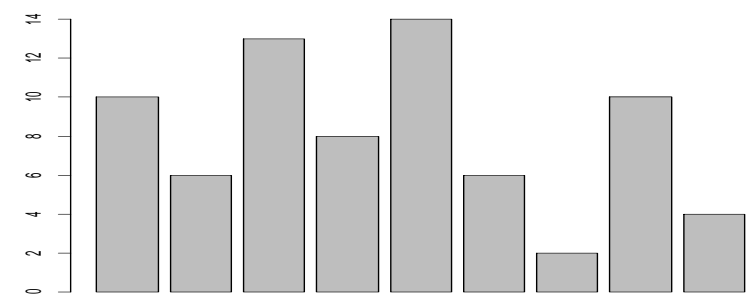

Figure 5 - Zone frequencies for the period 20/10/1954 until 01/06/1964. 
In what follows (Fig. 6) the plot of the survival probabilities ${ }^{>} w_{i}(n) \forall n \epsilon\{1,2, \ldots, 2500\}$ is given.

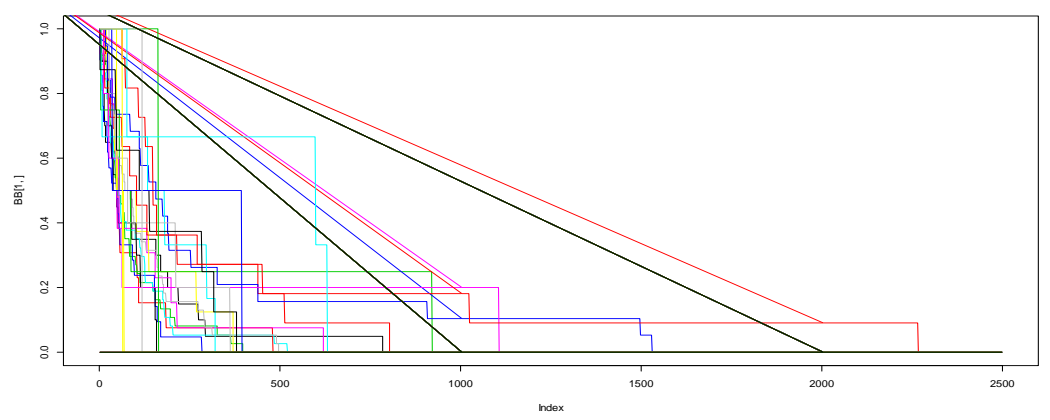

Figure 6 - Plot of the survival probabilities.

\section{Conclusions}

In the present paper a homogeneous semi Markov model is applied to data, referring to earthquake occurrences in the area of Japan through the time period 1900-2012. In the model a double state space, $\mathrm{S}=\left\{\left(Z_{i}, R_{j}\right) \mid \mathrm{i}=1, \ldots 9, \mathrm{j}=1,2,3\right\}$, where $Z_{i}$ defines the $\mathrm{i}$-th seismic zone and $R_{j}$ states the $\mathrm{j}$ th magnitude scale, is defined while the time unit of the model is one day. The maximum elements of $\mathbf{P}$, are corresponding to the transitions: (Z1,R3)--> (Z2,R1), (Z5,R3)--> (Z8,R2), (Z6,R3)--> (Z1 $, \mathrm{R} 2)$ and $(\mathrm{Z} 7, \mathrm{R} 1)-->(\mathrm{Z} 5, \mathrm{R} 1)$. The first three transition probabilities are equal to 1 and the fourth on $\mathrm{e}$ is equal to 0.625 . The implementation of the previous referred data produced interesting numerical results for the interval transition probabilities and the limiting state probabilities which were achieved within seven years. Limiting state probabilities for every state, is given by the limiting vector $\pi$, where $\pi=[0.061,0.031,0.081,0.036,0.087,0.040,0.025,0.116,0.018,0.055,0.026$, $0.149,0.023,0.031,0.003,0.018,0.032,0.116,0.004,0.011,0.032,0.000,0.002,0.003,0.000$, $0.000,0.000]$. The limiting probabilities for the states were low, as it was expected due to the definition of the state space. The maximum limiting probability for earthquake occurrence of large magnitude i.e. over 7.0 is 0.22 . An interesting remark resulted from calculating the moving average (Fig.4), is the indication of a time interval, in which earthquake occurrences are about 3 times more often than the rest. The mean holding time before the next earthquake, from 20/10/1954 until $01 / 06 / 1964$, is 48.3 days, compared to the mean holding time from all data which is 148 days.

\section{References}

Anagnos, T. and Kiremidjan, A.S., 1988. A review of earthquake occurrence models for seismic analysis, Probabilistic Engin. Mechanics, 3, 3-11.

Ando, M., 1975. Source mechanisms and tectonic significance of historical earthquakes along Nankai trough, Tectonophysics, 27, 119-140.

Cavers, M, and Vasudevan, K., 2015. Spatio-temporal Compex Markov Chains (SCMC) Model Using Directed Graphs: Earthquakes, Pageoph., 172, 225-241.

Howard, R.A., 1971. Dynamic Probabilistic Systems, Vol. II, Wiley.

Ito, T., Yoshioka, S. and Miyazaki, S., 1999. Interplate coupling in southwest Japan deduced from inversion analysis of GPS data, Phys. Erath Planet. Inter., 115, 17-34.

Ito, T., Yoshioka, S. and Miyazaki, S., 2000. Interplate coupling in northeast Japan deduced from inversion analysis of GPS data, Phys. Erath Planet. Inter., 176, 117-130.

Kanamori, H., 1977. Seismic and aseismic slip along subduction zones and their tectonic implications. In: Island Arcs, Deep Sea Trenches and Back-arc Basins, Amer. Geophys. Union, Washington D.C., 163-174. 
Karagrigoriou, A., Makrides, A., Tsapanos, T.M. and Vougiouka, G., 2015. Earthquake forecasting based on multi-state system methodology, Methodol. Comput. Appl. Probab., doi: 10.1007/s11009-015-9451-x.

Karakaisis, G.F., 2000. Effects on zonation on the results of the application of the regional time predictable seismicity model in Greece and Japan. Erath Planet, Space, 52, 221-228.

Knopoff, L., 1971. A stochastic model for occurrence of main sequences earthquakes, Rev. Geophys. Space Phys., 1, 175-198.

Lomnitz-Adler, J., 1983. A statistical model of the earthquake process, Bull. Seismol. Soc. Am., 73, 853-862.

Matsuda, T., 1981. Active faults and damaging earthquakes in Japan-macroseismic zoning and prediction fault zones. In: Earthquake Prediction, In: An international Review, Simpson, D.W. and Richards, P.G., eds., AGU, Washington D.C., 279-289.

Matsuda, T., 1990. Seismic zoning map of Japanese islands with maximum magnitudes derived from active fault data, Bull. Earthq. Res. Inst., Univ of Tokyo, 65, 289-314.

Musson, R.M.W., Tspanos, T.M. and Nakas, C.T., 2002. A power-law function for earthquake interarrival tome and magnitude, Bull. Seismol. Soc. Am., 92(5), 1783-1794.

Nava, F.A., Herrera, C., Frez, J. and Glowacka, E., 2005. Seismic Hazard Using Markov Chains: Application in Japan Area, Pageoph., 162,1347-1366.

Papazachos, B.C., Papdimitriou, E.E., Karakaisis, G.F. and Tsapanos, T.M., 1994. An application of the time-and magnitude-predictable model for long-term prediction of strong shallow earthquakes in the Japan area, Bull. Seismol. Soc. Am., 84, 426-437.

Sato, T., Hirotsuka, S. and Mori, J., 2012. Coulomb stress change for the normal fault aftershocks triggered near the Japan Trench by the $2011 \mathrm{M}_{\mathrm{w}} 9.0$ Tohoku-Oki earthquake, Earth Planets space, 64, 1239-1243.

Shcherbakov, R., Goda, K., Ivanian, A. and Atkinson, G.M., 2013. Aftershock statistics of major subductiion earthquakes, Bull. Seismol. Soc. Am., 103, 3222-3234.

Scordilis, E.M., 2006. Empirical global relatins converting Ms and mb to moment magnitude, $J$. Seismol., 10:225-236, doi: 10.107/s10950-006-9012-4.

Thatcher, W., 1984. The earthquake deformation cycle at Nankai trough, southwest Japan, $J$. Geophys. Res., 89, 3087-3101.

Tsapanos, T.M., 2001. The Markov model as a pattern for earthquakes recurrence in South America, Bull. Geolog. Soc. Greece, XXXIV/4, 1811-1617.

Tsapanos, T.M. and Papadopoulou, A.A., 1999. A discrete Markov model for earthquake occurrences in Southern Alaska, J. Balk. Geophys. Soc., 2(3), 75-83.

Vere-Jones, D., 1966. A Markov model for aftershock occurrence, Pageoph., 64, 31-42

Votsi, I., Limnios, N., Tsaklidis, G. and Papadimitriou, E., 2014. Hidden Semi-Markov Modeling f or the Estimation of Earthquake Occurrence Rates, Communications in Statistics-Theory an $d$ Methods, 43, 1484-1502.

Wesnouski, S.G., Scholz, C.H., Shimazaki, K. and Matsuda, T., 1984. Integration of geological and seismological data for the analysis of seismic hazard: A case study of Japan, Bull. Seismol. Soc. Am., 74, 687-708. 